\title{
Healthcare expenditure and fiscal sustainability: evidence from Switzerland
}

CARSTEN COLOMBIER, Dr. rer. oec.* THOMAS BRAENDLE, Dr. rer. pol.*

Preliminary communication**

JEL: H51, I13, I18

https://doi.org/10.3326.pse.42.3.3

\footnotetext{
* We thank the two anonymous referees and the editors for valuable comments and suggestions. The paper expresses solely the opinion of the authors.

${ }^{* *}$ Received: May 9, 2018

Accepted: July 3, 2018
}

\section{Carsten COLOMBIER}

University of Cologne, FiFo Institute for Public Economics; Federal Department of Finance, Bundesgasse 3, 3003 Bern, Switzerland e-mail: carsten.colombier@efv.admin.ch ORCiD: 0000-0002-1056-5772

Thomas BRAENDLE

University of Basel, Faculty of Business and Economics; Federal Department of Finance, Bundesgasse 3, 3003 Bern, Switzerland

e-mail: thomas.braendle@efv.admin.ch ORCiD: 0000-0002-2496-7000 


\section{Abstract}

Growing healthcare expenditure is of major concern for the sustainability of public finances. In order to better explore the fiscal sustainability challenge and to inform the debate, we draw up a new set of healthcare expenditure projections for the particularly interesting case of Switzerland. According to our projections up to 2045, population ageing exerts a growing pressure on public budgets and mandatory healthcare insurance. However, healthcare expenditure is not only driven by demographic change but also by non-demographic drivers such as the increasing national income, medical advances and Baumol's cost disease. We find that long-term care is more severely affected than healthcare excluding long-term care. This finding implies that population ageing affects public finances to a greater extent than the mandatory healthcare insurance. Our sensitivity analysis suggests that the strongest cost pressure comes from alternative assumptions about the future state of health and Baumol's cost disease. Accordingly, measures aiming at prevention and efficiency would help most to ease the pressure on public finances and mandatory healthcare insurance.

Keywords: healthcare expenditure growth, population ageing, long-term projections, sustainability, public finances, social insurance

\section{INTRODUCTION}

Across most advanced economies, health care expenditure has clearly outpaced economic growth in recent decades. This development is particularly evident in the US and in several European countries. While the US notably spends almost $17 \%$ of its income on healthcare, several European countries follow with the GDP share in question currently being at $12.1 \%$ in Switzerland, $11.2 \%$ in Germany and $11.1 \%$ in France (see figure 1).

\section{Figure 1}

Healthcare expenditure in an international comparison, 1990-2015 (in GDP\%)

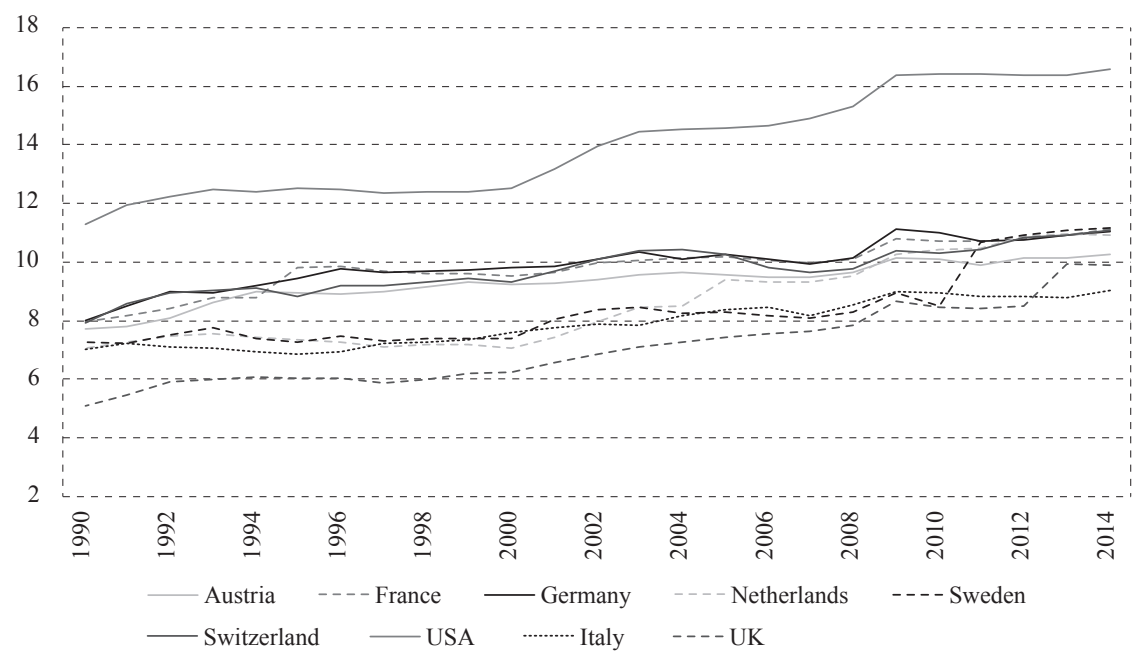

Source: OECD. 
In order to better explore the fiscal sustainability challenge and to inform the policy debate about measures to contain healthcare expenditure, we present a net set of projections focusing of the particularly interesting case of Switzerland. Switzerland has one of the most expensive healthcare systems among OECD countries and features a highly decentralized healthcare system. Moreover, the Swiss healthcare system is characterized by a particular financing scheme, i.e. a mixture of a mandatory (private) health insurance scheme and a relatively high share of public financing and private cost sharing.

Healthcare expenditure (HCE) in Switzerland has more than doubled over the last half-century or so, rising from 5.2\% of GDP in 1960 to $12.1 \%$ of GDP in 2015. While the annual average growth rate of GDP per capita amounted to $1.5 \%$, HCE per capita grew at a rate of $3.4 \%$. A decomposition of HCE by funding source shows that public finances and, in particular, the expenditure of the mandatory healthcare insurance (MHI) have come under increasing pressure from the rise of HCE (see figure 2).

\section{Figure 2}

Per-capita healthcare expenditure by funding source and per-capita GDP from 2000 to 2015 in Switzerland $(2000=100)$

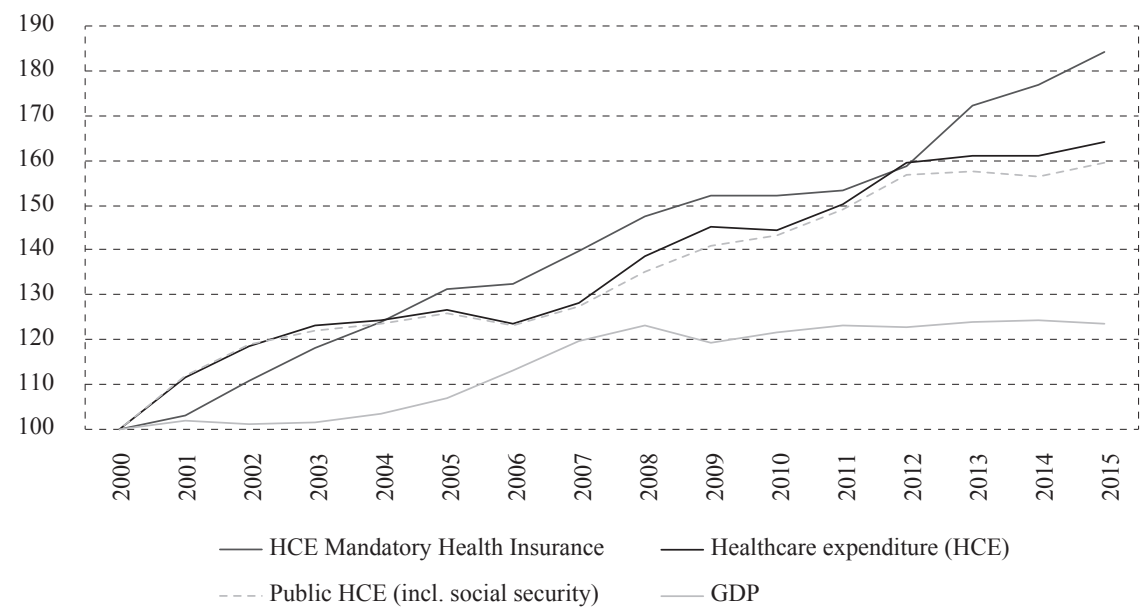

Source: Federal Statistical Office and Federal Finance Administration.

In this paper, we include a set of important drivers of HCE, i.e. ageing, income, medical progress as well as Baumol's cost disease for the projections. In all likelihood, population ageing increases the pressure on healthcare funding. Although the relative importance of population ageing as a determinant of HCE has been contested by some health economists (Zweifel, Felder and Meiers, 1999; Werblow, Felder and Zweifel, 2007), there is growing evidence for the relevance of population ageing as a driver of HCE (Gregersen, 2014; Breyer, Lorenz and Niebel, 2015; Colombier, 2018). Smith, Newhouse and Freeland, (2009:1281) explain "Demographics appear to have played a small role in the historical growth of 
spending but will loom larger with the ageing of baby boomers". An ageing population does not only exhibit greater demand for healthcare services and greater need for care services, but it also causes GDP growth to slow down because of the diminishing labour force. These developments are reflected in the "Reference scenario" of the Swiss Federal Statistical Office (FSO). The proportion of people over the age of 80 relative to the population is set to double from the current level of $5 \%$ to $10 \%$ by 2045 . A closely related question is how changes in life expectancy affect the health status of the population, thereby impacting HCE. Moreover, we take account of income development, advances in medical technology, and Baumol's cost disease - all determinants viewed as crucial by the literature (Martín et al., 2011; de la Maisonneuve and Oliveira Martins, 2013; Hartwig and Sturm, 2014). We apply income elasticity as a proxy for demand-side as well as supply-side effects, such as the demands of the population and advances in medical technology. Baumol's cost disease (Baumol, 1967) concerns the lower productivity development in healthcare that leads to additional cost pressure.

We draw up long-term projections of HCE that cover the period from 2013 to 2045. We use the latest demographic scenarios for Switzerland (FSO). In accordance with the practice of international institutions such as the OECD (de la Maisonneuve and Oliveira Martins, 2013; Marino et al., 2017) and the Ageing Working Group of the European Union (AWG, 2015), we apply a cohort approach and project HCE as a percentage of GDP. For the purposes of these projections, it is assumed that the currently prevailing health policies and institutions will not change ("no policy change"). Accordingly, while (cross-country) differences in the organization of the healthcare sector, e.g. different insurance and financing regimes, different compensation systems for providers and the role of general practitioner models, are likely to matter for healthcare cost growth, we take the existing institutional framework of the Swiss healthcare system as given.

Our projections show that population ageing exerts a growing pressure on public budgets and MHI. This development poses a threat to the sustainability of public finances (Braendle, Colombier and Philipona, 2016). However, not only does demographic change impact HCE but also non-demographic drivers such as the increasing national income and medical advances as well as Baumol's cost disease play a significant role. The results of this paper are comparable to those of the OECD (de la Maisonneuve and Oliveira Martins, 2013) and the EU AWG (2015). In particular, we find that long-term care (LTC) from the age of 65 is more severely affected than healthcare excluding long-term care $(\mathrm{HeL})$. This finding implies that population ageing affects public finances to a greater extent than it does affect MHI. A side-effect of continuously rising MHI premiums is undesirable distributional consequences. The financial burden of lump-sum per capita premiums is increasing for an ever-larger part of the population. Public finances are also adversely affected by premium increases through rising social benefits, i.e. individual premium reductions (IPR) to guarantee equal access to healthcare services for lower income households. Our findings suggest that cost-containment meas- 
ures that increase the efficiency of healthcare provision such as the avoidance of medically unnecessary treatments, a stronger reliance on capitation-based remuneration schemes, the introduction of E-health, allocation improvement between outpatient and inpatient care and fostering ambulatory and informal care can mitigate the pressure on MHI and public budgets. In addition, preventive measures and strengthening of the population's health competencies can contain HCE and ease, in particular, the pressure on public budgets. The projections are characterised by significant uncertainties such as the magnitude of the cost effects, and the modelling of non-demographic determinants in the healthcare system. The latter is particularly true for advances in medical technology. The objective is to provide a rough orientation for expenditure development and to highlight how sensitively expenditure development reacts to various cost drivers. For that reason, scenarios have been drawn up with differing assumptions regarding the impact of the relevant cost drivers.

This paper is organised as follows. Section 2 discusses the key cost drivers and describes the various scenarios. Section 3 sets out the projection methodology. Section 4 presents the main results of the projections for the total healthcare sector, the public sector and the mandatory insurance. Moreover, a comparison is drawn with the results for EU member countries. In concluding, section 5 discusses policy options to contain cost development in healthcare.

\section{DETERMINANTS AND SCENARIOS}

\subsection{COST DRIVERS}

In addition to the immediate repercussions of demographic change for healthcare expenditure, we include those effects that can have an expenditure impact as a result of a change in the health status (morbidity) due to increasing longevity. A number of different competing hypotheses have emerged in this respect. According to the thesis of pure morbidity extension, so-called "pure ageing", the additionally gained years of life are not spent in good health (Gruenberg, 1977). The state of health of the population deteriorates on average. The thesis of a relative reduction in morbidity, so-called "healthy ageing", states that the amount of time spent in a state of illness or in need of care does not change. However, it is also claimed that the extra years of life gained are spent in a good state of health (Manton, 1982). The thesis of an absolute reduction in morbidity in the event of rising life expectancy is put forward by Fries $(1980,1989)$, who argues that as a result of better technology and better prevention, the amount of a person's lifetime spent in sickness or in need of care can actually be reduced. The amount of time spent in good health rises more strongly than life expectancy. As there is no clear consensus in empirical studies with respect to the interaction of rising life expectancy and morbidity development, scenarios with different assumptions regarding the change in morbidity have been drawn up.

Aside from the effects of demographic change, the projections also include the effects of important non-demographic cost drivers. The first non-demographic 
factor to be taken into consideration is the empirically observable relationship between national income development and healthcare expenditure growth. This relationship covers both supply-side and demand-side effects, such as advances in medical technology and the demand of the population for healthcare services.

As advances in medical technology are very difficult to quantify from an empirical standpoint, it is assumed that the cost effect of advances in medical technology can be indirectly captured through the change in national income development. According to Smith, Newhouse and Freeland (2009), close interdependencies exist between advances in medical technology and national income: as a society becomes more prosperous, it may be assumed that its demand for medical innovations will rise ("demand pull"). At the same time, as a society becomes increasingly prosperous, so too is there an increase in selling opportunities for healthcare services, which has the effect of increasing the incentive to invest in research and development ("supply push"). Chandra and Skinner (2012) emphasize that medical advances can be converted into productivity gains if innovations are highly cost effective and effective new procedures are not overused. At the same time, treatments with uncertain and ineffective outcomes decelerate productivity growth and lead to increasing costs.

A key question is whether the demand for healthcare services (and therefore healthcare expenditure) rises disproportionately to income, thereby making healthcare services a so-called "luxury good". Early empirical analyses suggest that healthcare expenditure represents a so-called "necessary good" at an individual and a "luxury good" at an aggregated level (Gerdtham and Jönsson, 2000). However, there is no clear consensus on a precise assessment of income elasticity at aggregated level. Underlying problems are the comparability of the definitions of healthcare expenditure categories or the possible correlation of input prices and national income. Recent studies are often based on more comprehensive databases and use advanced empirical methods in order to address problems such as the omitted variable bias and endogeneity. These studies typically suggest an income elasticity of slightly below 1 (Baltagi and Moscone, 2010; Moscone and Tosetti, 2010; Costa-Font, Gemmill and Rubert, 2011; Acemoglu, Finkelstein and Notowidigdo, 2012; de la Maisonneuve and Oliveira Martins, 2013; Medeiros and Schwierz, 2013; Hartwig and Sturm, 2014). In the case of Switzerland, Colombier (2018) uses a time series analysis for total HCE to show a systematic, positive partial correlation with national income, whereby the corresponding income elasticity is around 1. For a cantonal panel dataset for the period 1970-2012, Braendle and Colombier (2016) find - in keeping with the results of the latest research literature - a robust partial correlation between income and cantonal healthcare expenditure, whereby the estimated income elasticity lies around 0.7 to 0.8 . Vatter and Rüefli (2003), who investigate the determinants of healthcare expenditure for a cross-section of cantons and communes for the years 1994-1999, find a positive partial correlation between cantonal income and public healthcare expenditure. Where MHI expenditure is concerned, the authors find a positive but not signifi- 
cant partial correlation. Crivelli, Filippini and Mosca (2006), and Reich et al. (2012) investigate the sum of cantonal healthcare expenditure and MHI expenditure at cantonal level. For a significantly shorter timeframe, namely 1996 to 2002 or 1997 to 2007 (due to the incorporation of MHI data), these studies do not find a statistically significantly positive correlation between cantonal income and HCE.

Another factor concerns productivity development in healthcare. This is difficult to measure empirically, and may indeed differ among healthcare sectors. For example, productivity advances in labour-intensive long-term care may be minimal, whereas in the more capital-intensive and technology-intensive hospital sector, productivity gains could reasonably be expected. Lower productivity growth relative to the overall economy results in cost pressure if healthcare wages keep step with wage growth in the remainder of the economy in the longer term. Given a relatively inelastic demand for healthcare services, healthcare prices accordingly rise more strongly than prices in the remaining economy. This price effect is known as Baumol's cost disease (Baumol, 1967). Empirical studies provide evidence that the Baumol effect is an important determinant of HCE (Colombier, 2017). However, the evidence regarding the extent of the Baumol effect is mixed. Some panel data analyses for OECD countries come to the conclusion that healthcare is completely contracted by the cost disease (Hartwig, 2008; Hartwig and Sturm, 2014). Based on a refined approach, Bates and Santerre (2013) for the US federal states and Colombier (2017) for OECD countries show that the cost disease is only partially relevant in healthcare. The same conclusion is reached by Colombier (2018) who uses time-series data from Switzerland.

Studies based on micro data provide evidence for the primary relevance of the proximity to death for healthcare costs (Zweifel, Felder and Meiers, 1999; Felder, Meier and Schmitt, 2000; Werblow, Felder and Zweifel, 2007). They suggest that population ageing per se barely affects HCE. While the proximity to death is relevant at the microeconomic level, its relative importance at macroeconomic level and, thus, for projection HCE is contested for the following reasons (e.g. de la Maisonneuve and Oliveira Martins, 2013). First, empirical evidence shows that the results of $\mathrm{HCE}$ projections do not substantially change if the proximity to death is included (Colombier and Weber, 2011; van Baal and Wong, 2012). Second, methodological concerns have been raised, such as the endogeneity between the explanatory variable proximity to death and HCE (Gregersen, 2014). Furthermore, ageing as a determinant becomes more relevant if a time-series dimension is added and ageing over time, a rising longevity, is included (Breyer, Lorenz and Niebel, 2015).

Differences in the organization of the healthcare sector, e.g. different insurance and financing regimes, different compensation schemes for providers, different regulations of healthcare markets and the role of general practitioner models, are likely to matter for healthcare cost growth (Bodenheimer, 2005; Hartwig and Sturm, 2014; de la Maisonneuve et al., 2017). However, under the no-policy 
change assumption, we take the existing institutional framework of the Swiss healthcare system as given.

\subsection{SCENARIOS}

We draw up different scenarios for the sectors of HeL and LTC from the age of 65 to take the uncertainties regarding the cost impact of the determinants into consideration.

With respect to the change in the population's state of health, it is assumed for the sector of HeL that the extra years of life gained are spent half in a good state of health and half in a poor state of health in the "Reference scenario". In addition, the increase in national income has a disproportionately high impact on the increase in healthcare expenditure through demand and supply-side effects. Leaning on the "AWG reference scenario" by AWG (2015:124-25) and empirical results for Switzerland (Colombier, 2018) an income elasticity of 1.1 is assumed. The Baumol effect is not factored into the considerations. Population growth is extrapolated in accordance with scenario A-00-2015 of the FSO. In the "Pure ageing" scenario, by contrast, it is assumed that the population spends the additional years of life gained in a poor state of health (extension of morbidity). In the "Healthy ageing" scenario, the population spends the extra years of life gained in good health (relative decrease in morbidity). In contrast to the "Reference scenario", the "Migration" scenario is based on demographic scenario A-06-2015, which assumes a higher net immigration rate. Due to the sharper increase in the working-age population, economic growth is stronger than in the reference scenario. In the "Baumol" scenario, unlike in the reference scenario, it is assumed that productivity advances in healthcare (excluding the long-term care sector) are some $40 \%$ lower than in the economy as a whole. In the "Expanded Baumol" scenario we assume for the sector of HeL a Baumol effect of $60 \%$. The productivity advance in the sector of HeL lags behind overall economic productivity advance by $60 \%$. The long-term care sector experiences a low advance in productivity (25\% of the overall economic average). Only $75 \%$ of the Baumol effect manifests itself in the long-term care sector. This figure is based on the level of staff costs as a proportion of overall costs in the care-home sector (Christian et al., 2015). In the "Cost pressure" scenario, is it assumed that non-demographic cost determinants gain in importance: advances in medical technology, an increase in doctor densities with a higher risk of supplier-induced demand given the asymmetric information between doctors and patients, and the increasing degree to which the population draws on healthcare services - trigger significantly stronger expenditure growth than in the "Reference scenario". This in turn translates into expenditure rising more strongly in the event of rising income. Based on the corresponding European Commission scenario, an income inelasticity of 1.4 is assumed (AWG, 2015).

The same assumptions regarding demographics and morbidity (i.e. the need for care) used for the sector of HeL are also applied to the scenarios for LTC from the 
age of 65. However, other than in the "Expanded Baumol" scenario, it is assumed in the scenarios for long-term care that no productivity advances are achievable, and that the Baumol effect is therefore fully effective. This is a standard assumption for projections of HCE (de la Maisonneuve and Oliveira Martins, 2013). In addition, no income effect comes into play in the long-term care sector, as the need for care is not voluntary and is independent of income. Accordingly, a no "Cost pressure" scenario is drawn up for the long-term care sector.

\section{METHODOLOGY ${ }^{1}$}

In accordance with the practice of international institutions such as the OECD and the European Commission, we apply a cohort approach and project HCE as a percentage of GDP. ${ }^{2}$

As a number of different cost drivers (or in some cases the same cost drivers) exercise their influence to a differing extent in different sectors of the healthcare system, the expenditure projections for healthcare expenditure are broken down into the sectors of HeL and LTC from the age of 65 . The residual sector is therefore that of long-term care for persons aged under 65. On the basis of this breakdown, the total expenditure of each sector is projected in a first step. In the next step, the proportion of healthcare expenditure financed by both the public sector and $\mathrm{MHI}$ are extrapolated along with the expenditure projected for the total healthcare sector.

The figures for healthcare expenditure are taken from the FSO's "Costs and Services of the Healthcare System" statistics. The most recent data available at the time the projections were drawn up date back to 2013, which is why this year forms the base year for the projections. The graphic illustration of expenditure per capita of population by age is described as the expenditure profile for a given year. For example, in figure 3 the expenditure profile for outpatient treatment in HeL for women is shown for the base year and for the year 2045 under the "Healthy ageing" scenario. In order to project expenditure for the HeL and LTC sectors, the expenditure profiles are further divided up by gender as well as by outpatient and inpatient treatment. Expenditure per capita of population can effectively be viewed as the price of supplying the population with healthcare services at a given level. This expenditure per capita of population can then be broken down into the price of services per patient on the one hand, and the scope of service (e.g. treatments, medications) per capita of population on the other. ${ }^{3}$ It is therefore assumed that demographic changes affect neither the cost side nor the scope of service per resident side. As a consequence, the cost effect of demographic change expresses

\footnotetext{
${ }^{1}$ For a detailed description of the projection methodology and the expenditure profiles, see Braendle and Colombier (2017:18-25).

${ }^{2}$ For a review on projection methodology see Pryzwara (2010).

${ }^{3}$ The expenditure per capita by age cohort can be broken down into a price effect and volume effect per patient treated on the one hand, and the probability of falling ill on the other: expenditure per service ("price") x utilisation per patient $\mathrm{x}$ patients per capita of an age cohort, whereby the product of utilisation per patient and patients per capita of an age cohort results in the scope of service per capita of an age cohort.
} 
how a change in the ageing structure of the population and the number of residents in Switzerland changes total demand for healthcare services. For simplicity's sake, expenditure on long-term care for those aged below 65 is extrapolated on the basis of the change in GDP.

\section{Figure 3}

Expenditure profile for outpatient treatment of women in HeL by age in the base year and in 2045 under the "Healthy ageing" scenario (CHF) - in thousands

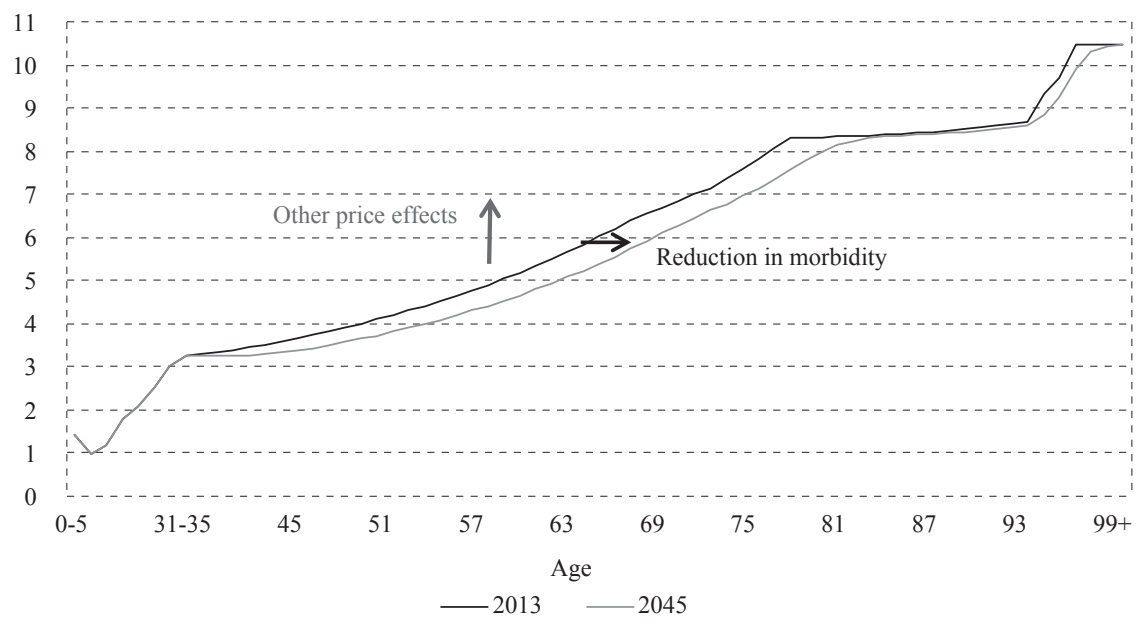

The starting point for the projections is the expenditure profiles broken down by age, gender, and outpatient or inpatient services (see figure 3). If the state of health of the population improves over the projection period, the expenditure per capita of an age cohort falls, and the expenditure profile shifts to the right (see figure 3 ). Here it is assumed that the probability of falling ill or requiring care declines. At the same time, this means that a change in morbidity influences neither the expenditure on a medical or care service, nor the degree of utilisation per patient. As the probability of falling ill or requiring care falls, however, so too does the scope of service per capita for an age cohort. The cost pressure exerted by nondemographic cost drivers such as advances in medical technology expresses itself in rising expenditure per capita of an age cohort. As a similar effect of non-demographic cost drivers is assumed for all age cohorts, the expenditure profile accordingly shifts upwards. ${ }^{4}$ This increase in expenditure is either caused by rising expenditure per service or by an increasing degree of utilisation per patient, or by a combination of the two, and has the effect of increasing the price of providing healthcare services. Changes in quality in the provision of services are not taken

\footnotetext{
${ }^{4}$ There are a number of indications to the effect that the expenditure profile steepens with time, and that the age cohorts are therefore affected to different degrees by the cost pressure of non-demographic cost drivers such as advances in medical technology (Gregersen, 2014). This could imply, for example, that research efforts to develop new medications are particularly focused on medications for the older age cohorts, as old people are disproportionately affected by serious illnesses such as cancer and cardiovascular disease.
} 
into account in this approach. ${ }^{5}$ Furthermore, in the sector of HeL, it is assumed that expenditure per capita remains constant for the age cohort "96 and over" due to limited data availability. In light of major differences in life expectancy at different ages, as well as between women and men, morbidity effects are determined not by the change in average life expectancy of the overall population, but by the change in life expectancy based on age and gender.

\section{RESULTS}

\subsection{TOTAL HEALTHCARE EXPENDITURE}

According to the "Reference scenario", expenditure will continue to rise from $10.8 \%$ of GDP in 2013 to $14.0 \%$ of GDP in 2045 (see figure 4). For the years 1995 to 2013 , health expenditure rose by around 2 percentage points of GDP (whereby GDP is cyclically adjusted). The average annual growth rate of total HCE amounted to $3.7 \%$. What is striking is that the annual growth rate of expenditure on LTC from the age of 65 outpaced expenditure on HeL by over 1 percentage point, i.e. $4.8 \%$ vs. $3.6 \%$.

\section{Figure 4}

Healthcare expenditure by sector from 1995 to 2013 and in the "Reference scenario" up to 2045 (in \% of GDP)

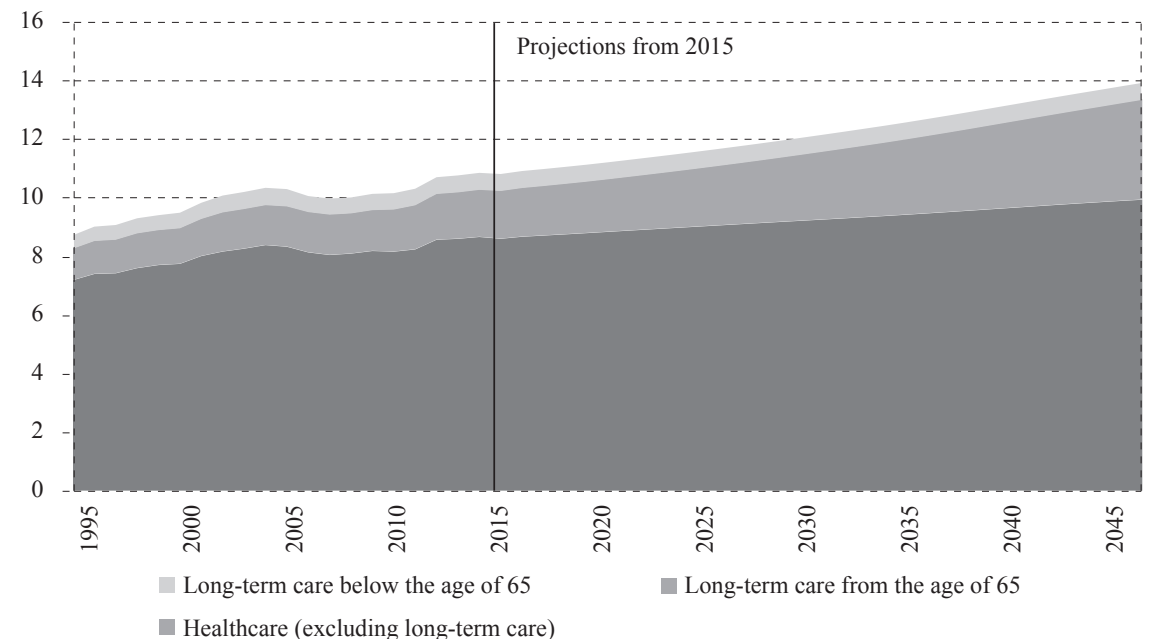

According to the "Reference scenario", the trend towards significantly higher expenditure growth for long-term care (from 65 years of age) than for healthcare excluding long-term care will continue in the future. Measured as a percentage of GDP, expenditure on long-term care (from the age of 65) more than doubles (rising from $1.6 \%$ to $3.4 \%$ of GDP), while healthcare expenditure rises from $8.6 \%$ to $9.9 \%$. On the one hand, demographic change (ageing, including the associated

\footnotetext{
${ }^{5}$ In the case of a price rise as a result of advances in medical technology, the extent to which the level of provision rises as a result of quality improvements is not clear. Potential quality improvements would have to be offset against the price effect in order to capture the effective price rise. This is an extremely challenging task even for past developments in HCE, and goes beyond the methodological approach selected here.
} 
change in the average state of health) feeds through into the long-term care sector to a much greater extent ( $72 \%$ of the rise in expenditure) than it does in the remaining healthcare sector (just under $60 \%$ of the rise in expenditure). ${ }^{6}$ On the other hand, expenditure on long-term care rises by $2.2 \%$ annually as a result of the Baumol effect, whereas expenditure on healthcare as a result of rising income per capita rises by just under $1.9 \%$ annually.

\subsection{PUBLIC HEALTHCARE EXPENDITURE}

Public expenditure on healthcare comprises all contributions of the federal government, cantons and communes, as well as the social security funds for financing healthcare. For each of the three levels of government, the expenditure figure in question is that contained under the "Health" section of the public finance statistics by the Federal Finance Administration (FFA). Also included are government transfers to private households designed to finance healthcare benefits, such as individual premium reductions and cantonal supplementary benefits for the old-age pensions. Furthermore, HCE of the social insurances for old-age (AHV) and disability (IV) are included. Just like overall expenditure, public healthcare expenditure is broken down into the sectors of healthcare excluding long-term care, and longterm care from the age of 65. Other public sector contributions to healthcare, such as preventive measures and administration, are extrapolated in line with GDP.

The public sector devotes the greatest proportion of its healthcare expenditure to hospitals (40\%), followed by individual premium reduction (IPR) (19\%), AHV supplementary benefits for care (9\%), care homes $(7 \%)$, and ambulatory care (4\%). The remaining contributions come from the social security funds and encompass the AHV allowance for the physically disabled (2\%) and IV expenditure on healthcare (9\%). A striking point to note according to the "Reference scenario" is that in 2045 the public sector will have to spend a far greater proportion of its budget on long-term care from the age of 65 . Instead of the current level of $23 \%$, the share of expenditure accounted for by care is projected to rise to $34 \%$ in 2045 . Accordingly, the proportion of expenditure accounted for by healthcare excluding long-term care is lower in 2045 , having declined from $68 \%$ to $61 \%$.

According to the "Reference scenario", general government expenditure rises over the projection timeframe continuously, namely from $3.5 \%$ of GDP to $4.2 \%$ of GDP in 2030, and up to $5.0 \%$ of GDP by 2045 . The lion's share of general government expenditure here is borne by the cantons, namely $68 \%$. For example, a good two thirds of the increase in public healthcare spending up to 2045 , or $1.1 \%$ of GDP, is shouldered by the cantons. Table 1 gives an overview of the projected healthcare expenditure growth by source of financing in the "Reference scenario".

\footnotetext{
${ }^{6}$ For a decomposition of the relative importance of HCE determinants in the various scenarios see appendix, figures $\mathrm{A} 1$ and $\mathrm{A} 2$.
} 
TABLE 1

Expenditure on healthcare by area and source of financing in reference scenario (in $G D P \%$ )

Level

2013

2030

2045

\begin{tabular}{|c|c|c|c|c|c|}
\hline & & Ratio & $\begin{array}{c}\text { Change } \\
2013-2030\end{array}$ & Ratio & $\begin{array}{c}\text { Change } \\
2013-2045\end{array}$ \\
\hline Total healthcare & 10.8 & 12.2 & +1.4 & 14.0 & +3.2 \\
\hline Healthcare excluding long-term care & 8.6 & 9.3 & +0.7 & 9.9 & +1.3 \\
\hline Long-term care (from the age of 65) & 1.6 & 2.3 & +0.7 & 3.4 & +1.8 \\
\hline Long-term care (below the age of 65) & 0.6 & 0.6 & 0.0 & 0.6 & 0.0 \\
\hline \multicolumn{6}{|l|}{ Source of financing } \\
\hline Government (incl. soc. sec. funds) & 3.5 & 4.2 & +0.7 & 5.0 & +1.5 \\
\hline Confederation & 0.4 & 0.5 & +0.1 & 0.5 & +0.1 \\
\hline Cantons & 2.4 & 2.9 & +0.5 & 3.5 & +1.1 \\
\hline Communes & 0.3 & 0.4 & +0.1 & 0.5 & +0.2 \\
\hline $\mathrm{AHV} / \mathrm{IV}^{*}$ & 0.4 & 0.3 & -0.0 & 0.4 & +0.0 \\
\hline Mandatory health insurance** & 3.3 & 3.7 & +0.4 & 4.1 & +0.8 \\
\hline Other expenditure $* * *$ & 4.0 & 4.3 & +0.3 & 4.8 & +0.9 \\
\hline of which: private households $* * * *$ & 2.6 & 2.9 & +0.3 & 3.3 & +0.7 \\
\hline
\end{tabular}

* Allowances for the helpless, contributions to medical services and therapeutic equipment.

** Excluding public expenditure on individual premium reductions, which are attributed to the general government sector.

*** Other expenditure contains the expenditure of private households, mandatory accident assurance (SUVA) and military insurance, supplementary insurances, private foundations and supplementary benefits of $I V$, which are not driven by ageing.

**** Cost contribution of OKP and out-of-pocket payments (OOP).

\section{Figure 5}

Public healthcare expenditure in various scenarios (in \% of GDP)

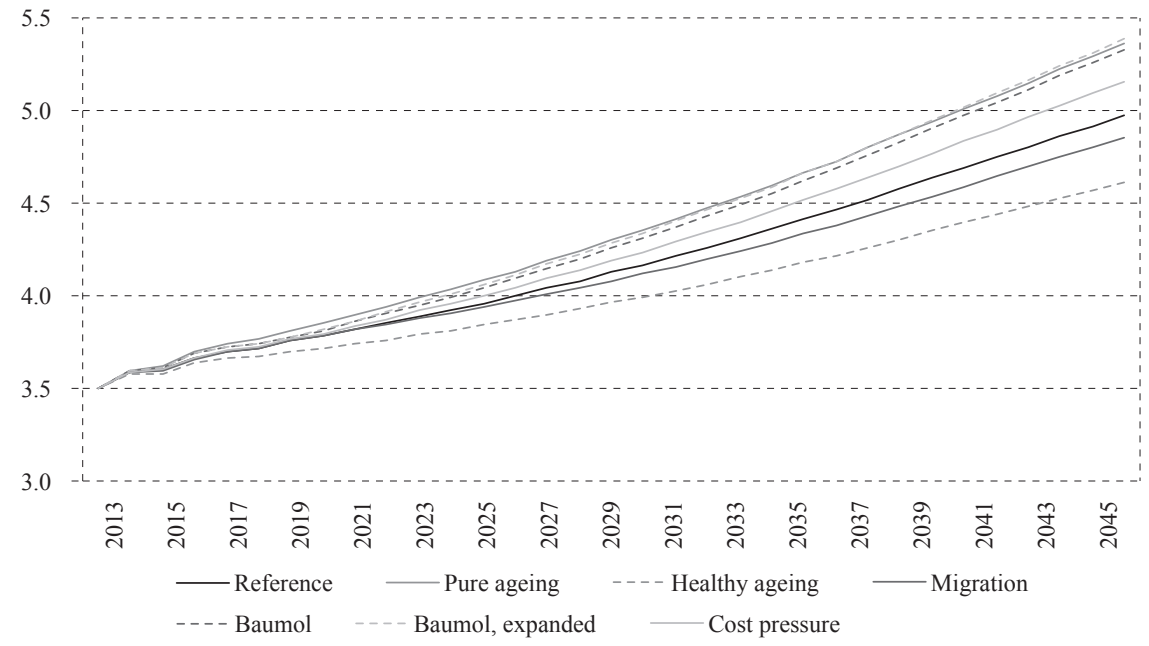

It can be seen in figure 5 that the rise in public healthcare expenditure works out differently depending on the scenario applied. The span between the most opti- 
mistic "Healthy ageing" scenario and the most pessimistic "Pure ageing" scenario amounts to a good $0.7 \%$ of GDP in 2045 . This is the equivalent of $15 \%$ of all expenditure of the public sector in the reference year 2045, or an inflation-adjusted CHF 7.7 billion.

The strongest impact on the development of public healthcare expenditure can be seen with a change in hypotheses concerning: (i) the relationship between the increase in the population's life expectancy and its state of health, and (ii) the assumption of a Baumol effect in the HeL sector. If it is assumed that while the population may be older in the future, it will be neither healthier nor less in need of care than the present population ("Pure ageing" scenario), expenditure as a percentage of GDP rises by almost a third compared to the "Reference scenario" in $2045(+0.4 \%$ of GDP). By contrast, if the population lives out its additional years of life in good health and does not require care during these years ("Healthy ageing" scenario), the increase in expenditure is around a third lower than in the "Reference scenario" (-0.4\% of GDP). Government expenditure rises slightly more than in the "Pure ageing" scenario if a substantial Baumol effect of $60 \%$ is assumed for HeL, together with lower productivity advances in the sector of longterm care from the age of 65 (25\% of average advance in productivity ("Expanded Baumol" scenario). The rise in expenditure works out almost as strong if a slightly weaker Baumol effect in the HeL sector is assumed, namely $40 \%$, together with a complete Baumol effect in long-term care ("Baumol" scenario). A rise in expenditure compared to the "Reference scenario" is likewise evident $(+0.2 \%$ of GDP) if stronger cost pressure on the part of non-demographic determinants is assumed ("Cost pressure" scenario), such as advances in medical technology. A higher net immigration rate than in the reference scenario ("Migration" scenario) has a slightly cost-restraining effect.

Overall, demographic change is more significant for public healthcare expenditure than it is for total healthcare expenditure. The reason for this is that the proportion of public expenditure accounted for by long-term care from the age of 65 is $23 \%$, much higher than in the overall healthcare sector (just under 15\%). Accordingly, a change in the state of health against a backdrop of increasing life expectancy has significant repercussions for general government expenditure. A change in nondemographic cost drivers (Baumol effect, income effect) has a particularly strong impact on general government expenditure in the hospitals sector. At around 40\%, the share of public sector expenditure accounted for by hospitals is currently relatively high when compared to the equivalent percentage of hospital expenditure for healthcare as a whole (just under $28 \%$ ).

\subsection{MANDATORY HEALTHCARE INSURANCE (MHI) EXPENDITURE}

For the purposes of the projections, MHI expenditure in the sectors of healthcare excluding long-term care and long-term care from the age of 65 is broken down into outpatient and inpatient services. For the base year, the breakdown of expenditure has been taken from the statistics of the Federal Statistical Office "Healthcare costs and financing by service and financing regime 2013". In order to avoid the 
problem of duplicating general government expenditure, MHI expenditure is presented after the deduction of individual premium reduction (IPR) expenditure. In addition, the cost contributions of private households (deductible, co-payments) has been deducted.

Although the starting level is at roughly the same level as for public healthcare expenditure (3.3\% vs. 3.5\% of GDP), MHI expenditure rises only half as much by $2045(+0.8 \%$ vs. $+1.5 \%$ of GDP). The latter is attributable to the fact that the proportion of dynamically developing long-term care expenditure is much lower for MHI (9\%) than it is for the general government (23\%) in the reference year 2013. When viewed by sector, the lion's share of the rise in expenditure in MHI by 2045 , or $+0.5 \%$ of GDP, is attributable to the HeL sector. The remaining increase of $+0.3 \%$ of GDP is accounted for by long-term care from the age of 65 .

Due to the high proportion of expenditure on healthcare excluding long-term care, MHI expenditure reacts very sensitively to changes in assumptions regarding the Baumol effect and other non-demographic cost drivers such as advances in medical technology (see figure 6). The stronger the Baumol effect in the HeL sector, the higher the rise in expenditure vis-à-vis the "Reference scenario". Accordingly, the increase in MHI expenditure in the "Expanded Baumol" scenario is $0.7 \%$ of GDP higher than in the "Reference scenario", while in the "Baumol" scenario it is $0.5 \%$ of GDP higher than in the "Reference scenario".

\section{Figure 6}

\section{MHI expenditure in various scenarios (in \% of GDP)}

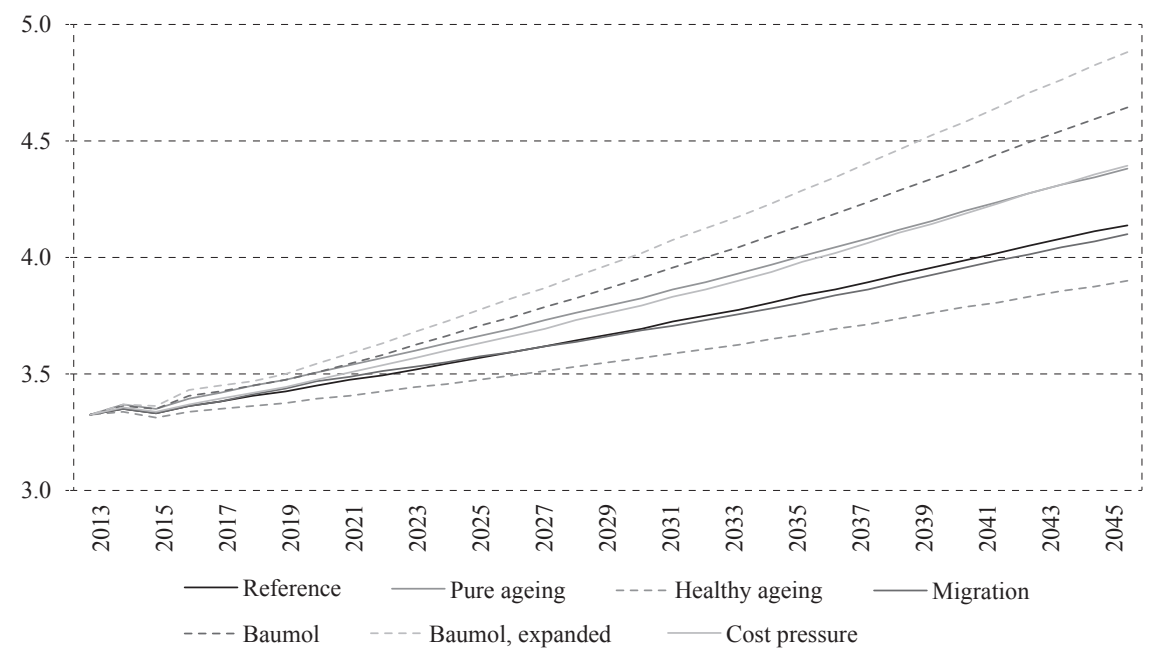

Higher pressure on costs, as would be the case as a result of advances in medical technology ("Cost pressure" scenario), for example, leads to a rise in expenditure of $0.3 \%$ of GDP. Expenditure rises similarly strongly if the assumptions regarding the development of the population's state of health and its need for care ("Pure ageing") are more pessimistic. The assumed morbidity development in the 
"Healthy ageing" scenario has an impact on the projections of a similar magnitude as in the "Pure ageing" scenario, but in this case it has a cost-restraining impact.

\subsection{COMPARISON WITH OTHER STUDIES}

The OECD presents projections of public HCE including the social health insurance for the member states of the OECD including Switzerland (de la Maisonneuve and Oliveira Martins, 2013). Whereas the OECD's projections of public expenditure on LTC from the age of 65 are very similar to the projections of this paper, the OECD projects a stronger rise in expenditure in the HeL sector. The OECD shows a rise in public HCE from 6.9\% (average of years 2006-2010) to 9.5\% of GDP for the year 2030 in the "Cost pressure" scenario, which assumes "no-policy change" (de la Maisonneuve and Oliveira Martins, 2013). In contrast, we project an increase in public HCE including MHI from $6.8 \%$ to $7.9 \%$ of GDP for the period from 2013 to 2030 in our "Reference scenario". A key aspect for the upward deviation is the modelling of medical advances. While medical advances are tied to the economic development through income elasticity in our projections, the OECD uses a residual approach and assumes that the unexplained part of the regression with public $\mathrm{HCE}$ as dependent variable is caused by the costs for medical advances. Moreover, the OECD uses an older more pessimistic population scenario and the base years differ.

With respect to the methodology and the selected scenarios, our projections are even closer to the work of the EU AWG (2015). For example, in the "AWG reference scenario" the assumptions concerning the morbidity of the population are the same as in our "Reference scenario" (see AWG, 2015:124-25).

\section{Figure 7}

Increase in public expenditure on healthcare and long-term care in an international comparison, 2013-2045 (in GDP\%)

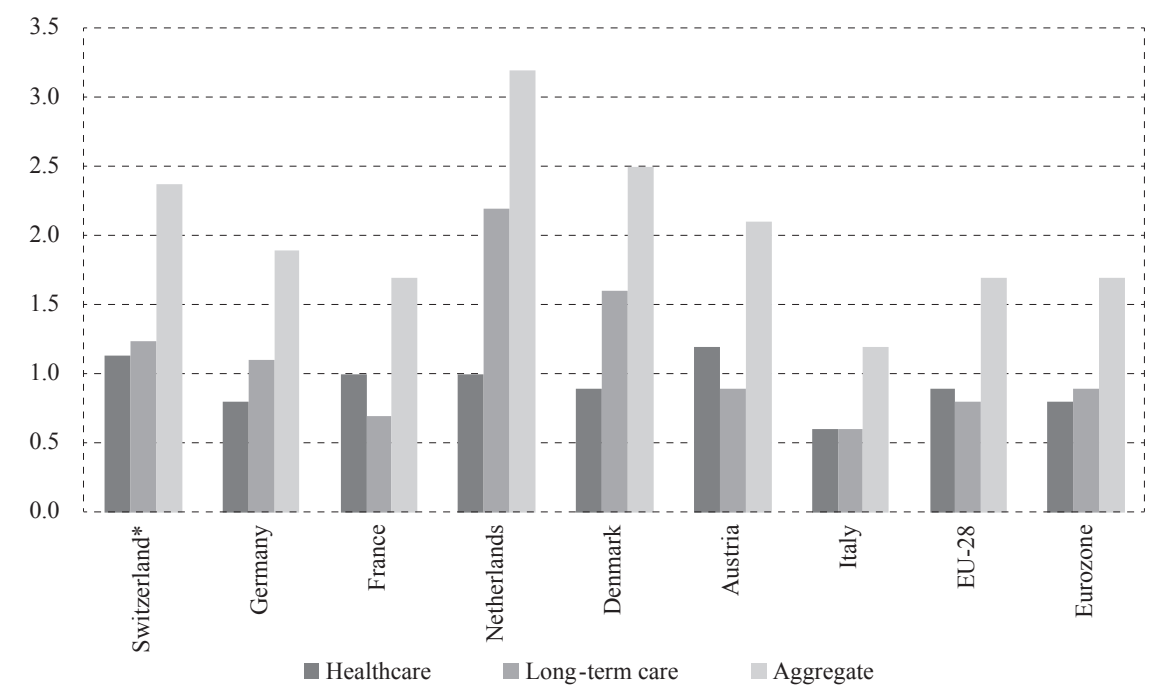

Note: * including mandatory healthcare insurance expenditure.

Source: $A W G$ (2015). 
The increase in public HCE including MHI by $2.4 \%$ of GDP works out higher in Switzerland than the average increase of the EU-28 and the Eurozone with 1.7\% of GDP respectively (see figure 7). In both sectors, HeL and LTC from the age of 65 the expenditure increase in Switzerland outlast the one in the Eurozone by $0.3 \%$ of GDP. The growth of public HCE including MHI is higher than in Germany, and puts Switzerland between Austria and Denmark. The comparatively lower increase of public HCE in EU countries may be explained by the fact that EU AWG assumes that the income elasticity in $\mathrm{HeL}$ initially starts at 1.1 but converges to 1.0 and that only a proportion of LTC services is affected by Baumol's cost disease. In contrast, we assume a constant income elasticity of 1.1 and a full Baumol effect. Additionally, one should bear in mind that country-specific demographic scenarios, the expenditure profiles in the base year and the national healthcare systems differ.

\section{DISCUSSION: MEASURES FOR COST CONTAINMENT}

Our projections show that population ageing adds to the unrelenting pressure on public budgets and MHI. However, in particular, in the sector of HeL, non-demographic determinants such as medical advances and national income growth contribute substantially to the dynamics of HCE. Demographic change affects the sector of LTC to a much greater degree than it does HeL. Since the LTC expenditure share of the public sector substantially outweighs the share of MHI (23\% vs. $9 \%$ ) population ageing affects the public sector stronger than MHI. As a result, a change in morbidity caused by an increasing life expectancy has a stronger impact on public finances. Therefore, the healthy ageing of the population is a crucial factor in alleviation of the cost burden on, particularly, public budgets. Accordingly, preventive measures such as improving nutrition and mobility habits and the strengthening of the population health's competencies that contribute to reducing chronic conditions are particularly important measures for cost containment. In addition, the different scenarios suggest that the pressure deriving from Baumol's cost disease is high. In such cases, efficiency-enhancing tools can prove particularly effective in reducing the pressure on MHI and public budgets.

Measures that help to avoid medically unnecessary treatments, improve the allocation of resources between outpatient and inpatient care and foster ambulatory and informal care to reduce the overcrowding of nursing homes can be effective. Given the coming demand for healthcare professionals, forward-looking personnel planning and the corresponding training of a sufficient number of healthcare professionals will be needed if costs are to be contained and the level of supply maintained (Merçay, Burla and Widmer, 2016).

Recent studies on cost-containment policies by Moreno-Serra (2010) and Schwierz (2016) suggest that supply side reforms such as more reliance on capitationbased fees, introducing budget caps and pharmaceutical policies can contribute to the mitigation of HCE growth. Budget caps can be introduced sector-wise or global-wise. In the first case the providers have more opportunities for cost-shift- 
ing. The main advantage of budget caps is that providers assume a budget responsibility that currently does virtually not apply to Swiss healthcare providers. However, budget caps may increase the risk of rationing and increased waiting times or increased referrals for secondary level healthcare institutions instead of treatment (e.g. Mihaljek, 2006; 2008 for specific country experiences). While in 2012 the per-diem rates in hospitals were replaced by diagnosis-related groups (Swiss DRG), practicing physicians are still remunerated by fee-for-services. This creates incentives for an over-supply of medically unnecessary treatments and reinforces the problem of supplier-induced demand due to asymmetric information between providers and patients. The introduction of capitation-based fees can reduce these incentives. On the demand side, a stronger role of the general practitioner as gatekeeper and the introduction of preferred drug lists have some success with respect to cost savings (Moreno-Serra, 2014). Ultimately, health technology assessment (HTA) that reviews treatments and drugs systematically may help to enhance the efficiency of healthcare and, as a result, curb costs.

\section{Disclosure statement}

No potential conflict of interest was reported by the authors. 


\section{Figure A1}

Contributions to inflation-adjusted rise in healthcare expenditure 2013-2045 (in \%)

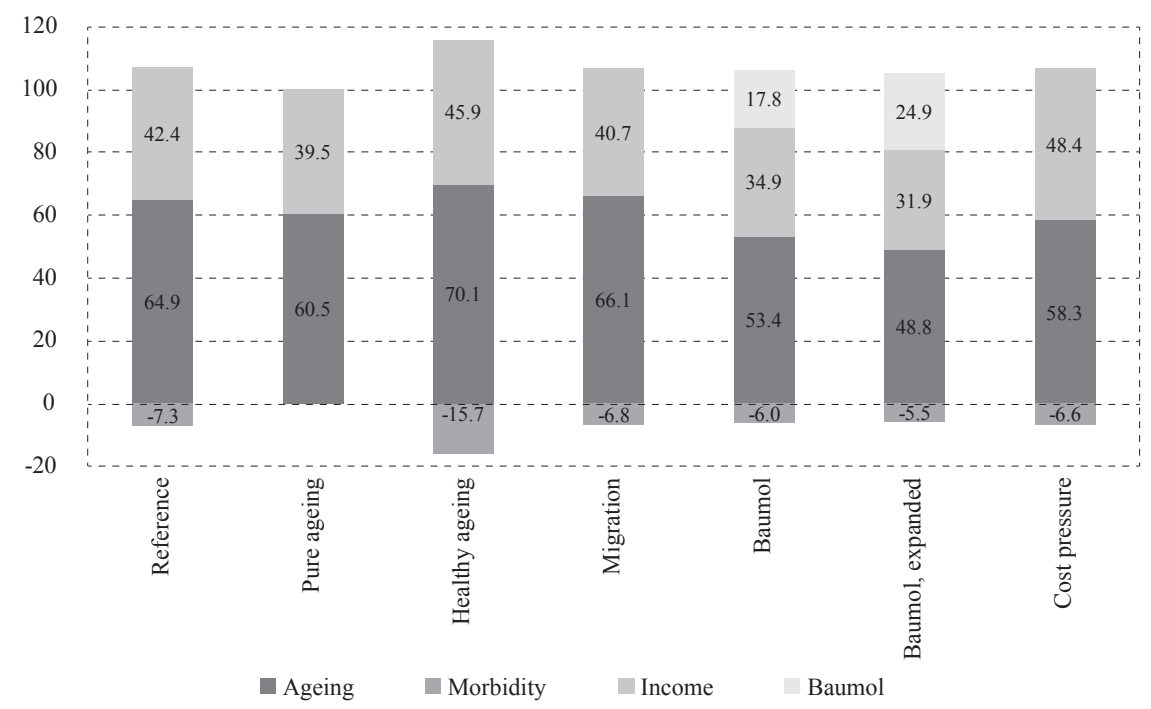

\section{Figure A2}

Contributions to the inflation-adjusted rise in expenditure on long-term care (from the age of 65) 2013-2045 (in \%)

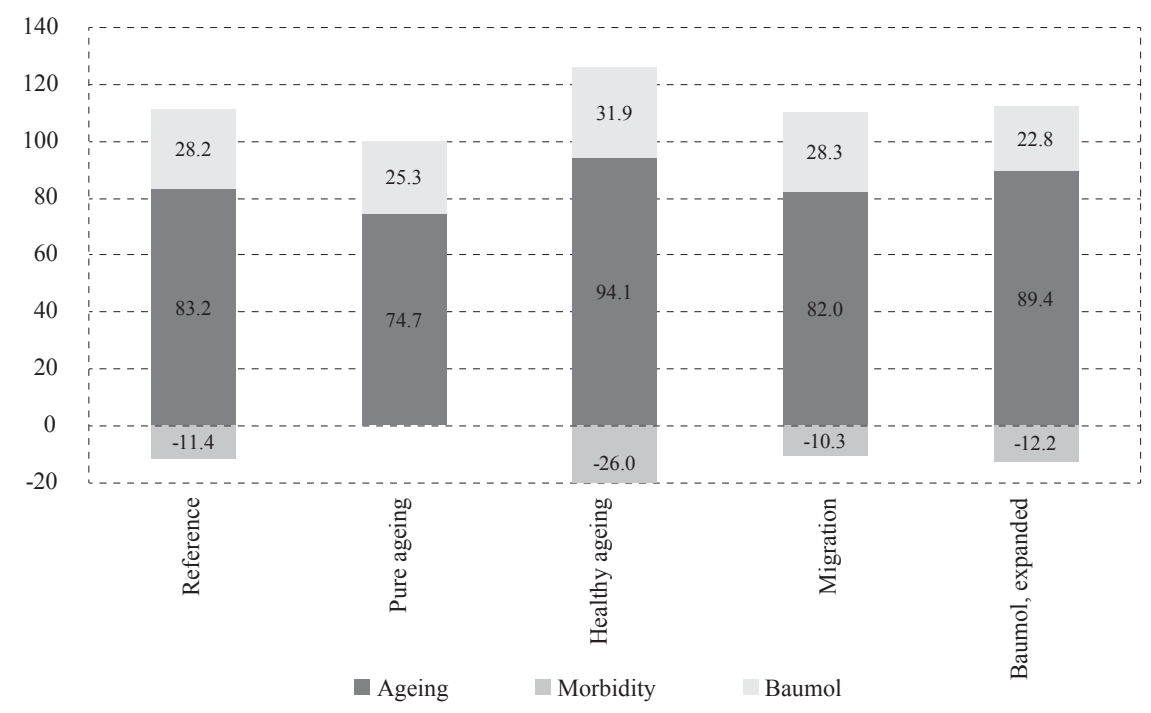




\section{REFERENCES}

1. Acemoglu, D., Finkelstein, A. and Notowidigdo, M. J., 2012. Income and Health Spending: Evidence from Oil Price Shocks. The Review of Economics and Statistics, 95(4), pp. 1079-95. https://doi.org/10.1162/REST_a_00306

2. AWG - Ageing Working Group of the Economic Policy Committee and the European Commission, 2015. 2015 Ageing Report. Economic and budgetary projections for the 28 EU Member States (2013-2060). Brussels: European Union. Available at: <http://ec.europa.eu/economy_finance/publications/european_economy/2015/pdf/ee3_en.pdf $>$

3. Baltagi, B. H. and Moscone, F., 2010. Health care expenditure and income in the OECD reconsidered: Evidence from panel data. Special Issue on Health Econometrics, Economic Modelling, 27(4), pp. 804-811.

4. Bates, L. J. and Santerre, R. E., 2013. Does the U.S. health care sector suffer from Baumol's cost disease? Evidence from the 50 states. Journal of Health Economics, 32(2), pp. 386-391.https://doi.org/10.1016/j.jhealeco.2012.12.003

5. Baumol, W. J., 1967. Macroeconomics of unbalanced growth: The anatomy of urban crisis. American Economic Review, 57(3), pp. 415-426.

6. Bodenheimer, T., 2005. High and rising health care costs. part 1: Seeking an explanation. Annals of Internal Medicine, 142(10), pp. 847-854. https://doi. org/10.7326/0003-4819-142-10-200505170-00010

7. Braendle, T. and Colombier, C., 2016. What drives public health care expenditure growth? Evidence from Swiss cantons, 1970-2012. Health Policy, 120(9), pp. 1051-60. https://doi.org/10.1016/j.healthpol.2016.07.009

8. Braendle, T. and Colombier, C., 2017. Healthcare expenditure projections up to 2045. Federal Finance Administration Working Paper, No. 21. Available at: <https://www.efv.admin.ch/dam/efv/en/dokumente/publikationen/arbeiten _oekonomenteam/workingpapers/Working_Paper_21_d.pdf.download.pdf/ Working_Paper_21_d.pdf>

9. Braendle, T., Colombier, C. and Philipona, A., 2016. 2016 Report on the LongTerm Sustainability of Public Finances in Switzerland. Bern: Federal Finance Administration. Available at: <https://www.efv.admin.ch/dam/efv/en/dokumente/publikationen/Langfristperspektiven $\% 20 \mathrm{der} \% 20 \% \mathrm{C} 3 \%$ B 6 ffentlichen \%20Finanzen\%20in\%20der\%20Schweiz\%202016.pdf.download.pdf/Langfristperspektiven $\% 20 \mathrm{der} \% 20 \% \mathrm{C} 3 \%$ B6ffentlichen $\% 20$ Finanzen $\% 20 \mathrm{in} \% 20$ der\%20Schweiz\%202016.pdf>

10. Breyer, F., Lorenz, N. and Niebel, T., 2015. Health care expenditures and longevity: is there a Eubie Blake effect? The European Journal of Health Economics, 16(1), pp. 95-112. https://doi.org/10.1007/s10198-014-0564-x

11. Chandra, A. and Skinner, J., 2012. Technology Growth and Expenditure Growth in Health Care. Journal of Economic Literature, 50(3), pp. 645-680. https://doi.org/10.1257/jel.50.3.645

12. Christian, A. [et al.], 2015. Gesundheitswesen Schweiz 2015 -Die Zukunft des Pflegeheimmarkts. Zurich: Investment Strategy \& Research - Economic Research. 
13. Colombier, C. and Weber, W., 2011. Projecting health-care expenditure for Switzerland: further evidence against the 'red-herring' hypothesis. The International Journal of Health Planning and Management, 26(3), pp. 246-263. https://doi.org/10.1002/hpm.1068

14. Colombier, C., 2017. Drivers of Health-Care Expenditure: What Role Does Baumol's Cost Disease Play? Social Science Quarterly, 98(5), pp. 1603-1621. https://doi.org/10.1111/ssqu.12384

15. Colombier, C., 2018. Population ageing in healthcare - a minor issue? Evidence from Switzerland. Applied Economics, 50(15), pp. 1746-1760. https:// doi.org/10.1080/00036846.2017.1374538

16. Costa-Font, J., Gemmill, M. and Rubert, G., 2011. Biases in the healthcare luxury good hypotheses?: a meta-regression analysis. Journal of the Royal Statistical Society. Series A (Statistics in Society), 174(1), pp. 95-107. https:// doi.org/10.1111/j.1467-985X.2010.00653.x

17. Crivelli, L., Filippini, M. and Mosca, I., 2006. Federalism and regional health care expenditures: an empirical analysis for the Swiss cantons. Health Economics, 15(5), pp. 535-541. https://doi.org/10.1002/hec.1072

18. de la Maisonneuve, C. and Oliveira Martins, J., 2013. "A Projection Method for Public Health and Long-Term Care Expenditures.” OECD Economics Department Working Paper 1048. https://doi.org/10.1787/5k44v53w5w47-en

19. de la Maisonneuve, R. M.-S., Murtin, F. and Oliveira Martins, J., 2017. The role of policy and institutions on health spending. Health Economics, 26, pp. 834-843. https://doi.org/10.1002/hec.3410

20. Felder, S., Meier, M. and Schmitt, H., 2000. Health care expenditure in the last months of life. Journal of Health Economics, 19(5), pp. 679-695. https://doi. org/10.1016/S0167-6296(00)00039-4

21. Fries, J. F., 1980. Aging, Natural Death, and the Compression of Morbidity. New England Journal Medicine, 303(3), pp. 130-135. https://doi.org/10.1056/ NEJM198007173030304

22. Fries, J. F., 1989. The compression of morbidity: near or far? The Milbank Quarterly, 67(2), pp. 208-232. https://doi.org/10.2307/3350138

23. Gerdtham, U.-G. and Jönsson, B., 2000. "International comparisons of health expenditure; Theory, data and econometric analysis" In: Handbook of Health Economics, pp. 11-53. https://doi.org/10.1016/S1574-0064(00)80160-2

24. Gregersen, F. A., 2014. The impact of ageing on health care expenditures: a study of steepening. The European Journal of Health Economics, 15(9), pp. 979-989. https://doi.org/10.1007/s10198-013-0541-9

25. Gruenberg, E. M., 1977. The Failures of Success. The Milbank Memorial Fund Quarterly. Health and Society, 55(1), pp. 3-24. https://doi.org/10.2307/ 3349592

26. Hartwig, J. and Sturm, J. E., 2014. Robust determinants of health care expenditure growth. Applied Economics, 46(36), pp. 4455-4574. https://doi.org/10.10 $80 / 00036846.2014 .964829$ 
27. Hartwig, J., 2008. What drives health care expenditure? Baumol's model of 'unbalanced growth' revisited. Journal of Health Economics, 27(3), pp. 603623. https://doi.org/10.1016/j.jhealeco.2007.05.006

28. Manton, K. G., 1982. Changing Concepts of Morbidity and Mortality in the Elderly Population. The Milbank Memorial Fund Quarterly. Health and Society, 60(2), pp. 183-244. https://doi.org/10.2307/3349767

29. Marino, A. [et al.], 2017. Future trends in health care expenditure. A modelling framework for cross-country forecasts. OECD Health Working Papers, No. 95. Available at: http://www.oecd.org/officialdocuments/publicdisplaydo cumentpdf/?cote $=$ DELSA/HEA/WD/HWP(2017)5\&docLanguage $=$ En

30. Martín, J. J. M. [et al.], 2011. Review of the literature on the determinants of healthcare expenditure. Applied Economics, 43(1), pp. 19-46. https://doi.org/ $10.1080 / 00036841003689754$

31. Medeiros, J. and Schwierz, C., 2013. Estimating the drivers and proejcting long-term public health expenditure in the European Union: Baumol's cost disease revisited. European Economy Economic Papers, No. 507. Available at: $<$ http://ec.europa.eu/economy_finance/publications/economic_paper/2013 $/$ pdf/ecp507_en.pdf $>$

32. Merçay, C., Burla, L. and Widmer, M., 2016. Gesundheitspersonal in der Schweiz. Bestandesaufnahme und Prognosen bis 2030. Obsan Bericht, No. 71. Available at: <https://www.obsan.admin.ch//sites/default/files/publications/ 2016/obsan_71_bericht.pdf>

33. Mihaljek, D., 2006. Health Care Policy and Reform in Croatia: How To See the Forest for the Trees in: K. Ott, ed. Croatian Accession to the European Union, pp. 277-320.

34. Mihaljek, D., 2008. Health-Care Financing Reforms in Central and Eastern Europe: Common Problems and Possible Approaches. http://dx.doi.org/ $10.2139 / \mathrm{ssrn} .1997204$

35. Moreno-Serra, R., 2014. The impact of cost-containment policies on health expenditure: Evidence from recent OECD experiences. OECD Journal on Budgeting, 13(3), pp. 1-29. https://doi.org/10.1787/budget-13-5jxx2wl6lp9p

36. Moscone, F. and Tosetti, E., 2010. Health expenditure and income in the United States. Health Economics, 19(12), pp. 1385-1403. https://doi.org/10.1002/ hec. 1552

37. Przywara, B., 2010. Projecting future health care expenditure at European level: drivers, methodology and main result. European Economy Economic Papers, No. 417. Available at: <http://ec.europa.eu/economy_finance/publications/economic_paper/2010/pdf/ecp417_en.pdf $>$

38. Reich, O. [et al.], 2012. Exploring the disparities of regional health care expenditures in Switzerland: some empirical evidence. The European Journal of Health Economics, 13(2), pp. 193-202. https://doi.org/10.1007/s10198-0110299-x 
39. Schwierz, C., 2016. Cost-Containment in Hospital Expenditure in the European Union. European Economy Discussion Paper, No. 37. Available at: $<$ https://ec.europa.eu/info/sites/info/files/dp037_en.pdf $>$

40. Smith, S., Newhouse, J. P. and Freeland, M. S., 2009. Income, Insurance, And Technology: Why Does Health Spending Outpace Economic Growth? Health Affairs, 28(5), pp. 1276-1284. https://doi.org/10.1377/hlthaff.28.5.1276

41. van Baal, P. H. and Wong, A., 2012. Time to death and the forecasting of macro-level health care expenditures. Some further considerations. Journal of Health Economics, 31(6), pp. 876-887. https://doi.org/10.1016/j.jhealeco. 2012.08.003

42. Vatter, A. and Rüefli, C., 2003. Do Political Factors Matter for Health Care Expenditure? A Comparative Study of Swiss Cantons. Journal of Public Policy, 23(3), pp. 301-323. https://doi.org/10.1017/S0143814X03003143

43. Werblow, A., Felder, S. and Zweifel, P., 2007. Population ageing and health care expenditure: a school of 'red herrings'? Health Economics, 16(10), pp. 1109-1126. https://doi.org/10.1002/hec.1213

44. Zweifel, P., Felder, S. and Meiers, M., 1999. Ageing of population and health care expenditure: a red herring? Health Economics, 8(6), pp. 485-496. https:// doi.org/10.1002/(SICI)1099-1050(199909)8:6<485::AID-HEC461> 3.0.CO; $2-4$ 